A series of papers dealt with photoperiodism in animals. Dr. A. D. Lees (A.R.C. Unit of Insect Physiology, Cambridge) reviewed the phenomena of photoperiodism in insects and mites, particularly in relation to the onset of diapause. Photoperiodic responses appear to be widespread in Lepidoptera. Dr. C. E. Jenner (University of North Carolina) dealt with photoperiodism in an aquatic midge, the larval stage of which is found in the 'pitchers' of pitcher plants. Reproduction in certsin snails and freshwater shrimps appears to require long-day conditions. Photoperiodism is also of importance in many marine invertebrates, including crustaceans, molluses and ochinoderms, as was shown by Dr. A. C. Giese (Stanford University).

The general problem of the seasonal control of reproductive cycles in vertebrates was discussed by Dr. W. S. Bullough (University of London), who emphasized that photoperiodism constitutes only one aspect of a highly complex system. In vertebrates, photoperiodic perception appears generally to be mediated through the eyes. In carp and related fishes, courtship and breoding appear to be induced by increasing day-length in the spring, as shown by Dr. R. W. Harrington (Floride State Board of Health). Photoperiodic effects have also been reported in certain reptiles, including the pond-turtle, the American chameleon and certain lizards. Dr. G. A. Bartholomew (University of California, Los Angeles) emphasized, however, that in the latter the importance of photoperiodic responses is probably over-ridden by behavioural patterns in relation to diurnal temperature changes.

Endogenous rhythms in the ovulation cycle of hens were described by Dr. R. M. Fraps (U.S. Dept. of Agriculture, Beltsville). Dr. D. S. Farner (State College of Washington) showed that in certain birds day-length controls a variety of physiological responses including the male gonadal cycle, fat metabolism, vernal migration and probably moulting. In the white-crowned sparrow the most effective spectral region controlling development of the testes appears to be in the red. Dr. A. Wolfson (North Western University, Evanston) described photoperiodic control of migration in the juncos of Alberta, in which fat deposition appears to be an important factor. The responses in these birds appear to be determined by the duration of the daily dark period.
Photo-periodic responses in other bird species were described by W. L. Engels (University of North Carolina), Dr. C. M. Kirkpatrick (Purdue University) and Dr. W. O. Wilson (University of California, Davis).

A further series of papers was devoted to endogenous rhythms in plants and animals. Dr. E. Bünning (University of Tübingen) gave a general account of endogenous rhythms, and discussed some general properties of the 'timing mechanism' in such rhythms. Dr. K. C. Hamner (University of California, Los Angeles) described the results of experiments with 'Biloxi' soybean, in which it was found that flowering occurred with cycle-lengths of 24 hours or of multiples thereof, whereas with cycles of intermediate duration flowering was partially or completely inhibited. These results are held to indicate an endogenous rhythm in photoperiodic sensitivity. Dr. F. W. Went (California Institute of Technology) showed that certain species, notably the tomato, made favourable growth on 24-hour cycles but showed reduced growth and other adverse symptoms on other lengths of cycle. These effects are exhibited in both photoperiodic and thermoperiodic phenomena.

Dr. C. S. Pittendrigh (Princeton University) discussed the possible nature of the clock mechanism in endogenous rhythms and postulated that two types of 'oscillator' may be involved, namely: (1) a primary light-sensitive oscillator which is temperature-independent, and the phase of which is determined by external light conditions; (2) a temperature-sensitive oscillator which can 'entrain' oscillator (1). Endogenous rhythms of activity in the hamster, and of bioluminescence in Gonyaulax polyedra, were described by Dr. K. S. Rawson (University of Wiscon$\sin$ ) and Dr. J. W. Hastings (Northwestern University) respectively.

Three evening sessions were devoted to sixteen short papers, including seven dealing with interactions between gibberellic acid and various lightcontrolled processes.

This highly successful meeting is believed to have constituted the first international symposium devoted specifically to photoperiodism in plants and animals. Biologists working in this field are indebted to the Photobiology Committee for organizing the meeting and especially to Dr. R. B. Withrow and Dr. N. E. Tolbert, chairman and secretary of the Committe respectively.
P. F. WAREING

\title{
FARMING HISTORY
}

$\mathrm{T}$ HE joint annual conference of the British Agricultural History Society and the Association of Agriculture was held on December 7 at the Institute of Education, University of London. Three papers were read. Mr. George Ordish discussed the "History of Crop Pests, and the Messures taken to overcome them". After lunch, two papers on horticultural history were presented. Dr. L. G. Bennett, Depart. ment of Agricultural Economics, University of Reading, spoke on the "History of the Development of Market Gardening", and Mr. Eric Hobbis, of Long Ashton Research Station, University of Bristol, on the "History of Soft Fruit Growing".

Pests and diseases of plants are as ancient as the cultivation of crops for food, and the uncultivated flora that flourished before man was probably also afflicted. Mr. Ordish showed by exhaustive references to Pliny that pests and diseases were well known in classical times. Apples and pears were affected, and the olive fly was prevalent. It is still a trouble. There were cereal pests, wireworm and the cabbage flea beetle, but there was no phylloxera, nor the two mildews that were introduced from America much later.

Methods of protection were then of four kinds : religious, superstitious, mechanical and chemical. Though some of the first two were peculiar, it is not advisable to dismiss them out of hand. The superstition of yesterday often turns out to be the science of to-day. Achilles barley, presumably an immune variety, was recommended by Pliny when rust was very bad. Treating with burnt ash, steeping seed in 
wine and the dregs from the oil presses were other preventive measures. Greasebands were fixed on the vines, and indeed are still used in Turkey.

No doubt the prevalence of pests and diseases, and the lack of knowledge of how to destroy or cure them, was a factor, among others, that kept yields at a low level for a thousand years or more.

Mr. Ordish proceeded to a discussion of the work of the sixteenth- and seventeenth-century botanists, more particularly that of Thomas Mouffett and Topsell. He said that Worlidge in 1669 had set out a method of dealing with hop mildew that would effectively control one type. The belief in the spontaneous generation of bugs, lice and other insects "out of corruption" was widely held by writers of that date, and was not disposed of until later scientists had shown that these pests were born out of eggs. New material had become available in the eighteenth century, and Richard Weston and others suggested the use of tobacco dust, spraying with a nicotine solution, and fumigating with tobacco smoke. Steeps of brine and urine had continued to be used to control cereal rusts, but there was some dispute about their efficacy. Some remarkable randomized experiments were made by Tilly in France about 1750 to test controls.

Necessarily, Mr. Ordish's paper was an outline of a vast subject, and, as was then said, it is to be hoped that he will make and publish an exhaustive study of the subject. The only existing treatise is a very brief American publication.

Dr. Bennett traced the development of commercial market gardening from the sixteenth to the nineteenth century. Before 1500 he thinks there was little. The use of vegetables is said to have declined. between the eleventh and the sixteenth centuries, and to have been revived only with the new methods of cultivation introduced to Great Britain by French and Dutch refugees from religious persecution. It is, however, a little difficult to accept this conclusion, because, if it is true, some other food must have taken the place of the onion, garlic, leek, cabbage, peas and beans, worts and other herbs that all went into the pottage commonly consumed by the gener- ality of the people. Be that as it may, Dr. Bennett made it quite clear that there was a great extension of market gardening in the sixteenth century. The refugees settled in the Sandwich area and elsewhere in Kent, around Norwich, and eventually in the immediate environs of London, where a part of Covent Garden was set aside for a vegetable and fruit market held three days a week. The Worshipful Company of Gardeners was organized by the growers to exercise control over malpractices and to look after their interests. From this time market gardening increased in importance, especially in the nineteenth century, when the growth of population in larg $\theta$ aggregations, some rise in the standard of living, and chang 35 in dietetic taste led to an immensely increased demand for fruit and vegetables.

Mr. Hobbis indicated no such decline in the use of soft fruits during the Middle Ages as there may have been in vegetables and herbs. Strawberries, raspberries and gooseberries were known to our remote ancestors, but the raspberries were not very well liked until the sixteenth century. They were thought sour. Red currants were then regarded as a small kind of red gooseberry. From such small beginnings a very large soft-fruit growing industry had developed by the nineteenth century, and it expanded widely during that century, though it had not then spread to the eastern counties. The two wars had a bad effect, but the soft-fruit growing industry under modern influences-factory jam-making, canning, deep freezing, and so on-is reviving, while the results of research are providing growers with advantages unknown to their predecessors.

Such subjects are not simple, and it is difficult to make a summary of all the important points raised in these two lectures and the discussion that followed them. All three lecturers demonstrated that there are large areas in the history of agriculture and horticulture that still require exploration.

The headquarters of the British Agricultural History Society have now been moved to the Department of Agriculture, Parks Road, Oxford, and anyone interested should make inquiries of the Hon. Secretary at that address. G. E. FUSSELL

\section{GELATINE AND GLUE}

A $T$ the fourteenth meeting of the Research Panel of the British Gelatine and Glue Research Association, held on December 12, Dr. S. M. Partridge (Low Temperature Research Station) took the chair for the morning session and Mr. S. G. Hudson (Richard Hodgson and Sons, Ltd.) for the afternoon session. The first paper was by Mr. G. Russell (Ilford, Ltd.) with the title "Chemically Distinct Major Components of Gelatin"1. He outlined previous views on the level of impurities (other than inorganic ions) in high-grade gelatines. Methods such as heat cosgulation, or adsorption on charcoal, suggest a protein impurity-level of not more than 0.5 per cent. In an attempt to separate these impurities from gelatin, experiments were carried out, in which chromatographic column technique was applied, using a finely divided form of the resin, 'I.R.C.50'. Elution was effected with a buffer previously used for equilibrating the column, so that the whole operation took place at the same $p H$. Protein in the fractions was estimated, after hydrolysis, by reaction with ninhydrin.
Whereas at $p \mathrm{H} 6$ the whole of the gelatin sample is eluted, giving a curve of concentration against eluant volume with a twin peak, at $p H \mathbf{H} 5 \cdot 5$ only a portion of the sample (15 per cent) is eluted, the remainder (85 per cent) being firmly adsorbed on the resin. The latter fraction can be removed by raising the $p H$. Paper chromatograms show the smaller component to have a higher tyrosine content than ordinary gelatin, no detectable hydroxyproline, and other characteristics giving it an amino-acid composition broadly similar to the serum albumins. The major component is similar to gelatin. Quantitative results for tyrosine, using ultra-violet absorption, show the major component to have zero or only a trace of tyrosine, whereas the minor component has about 3 per cent. Assuming the tyrosine to be entirely present in the minor component, the content of this component in a series of gelatins ranges from 10 to 20 per cent. Mr. Russell considered some of the implications of his work, and a keen discussion showed the interest aroused. Dr. G. R. Tristram (University 